\title{
Exploring the efficacy of pre-service teachers as makers of virtual language/culture learning environments
}

\author{
Sabrina Priego ${ }^{1}$ and Meei-Ling Liaw ${ }^{2}$
}

\section{Abstract}

$\mathrm{P}$ revious literature in the area of computer assisted language learning in Second/ Foreign Language (L2/FL) education has highlighted the benefits of using virtual environments for learning the target language and culture (e.g. Blyth, 2018; Lloyd, Rogerson, \& Stead, 2017; Shih, 2015). In addition, a number of researchers have demonstrated that one of the important attributes of virtual environments for language learning is the affordances of physical and social presence (e.g. Cho, Yim, \& Paik, 2015; McKerlich, Riis, Anderson, \& Eastman, 2011; Peterson, 2011; Wang, Lawless-Reljic, Davies, \& Callaghan, 2011). However, to our knowledge, no previous studies have investigated the affordances of virtual environments from the makers' point of view. In this present study, 22 Canadian pre-service teachers used a 360 degree camera and Virtual Reality (VR) software to construct VR environments that were used as cultural virtual tours. They then invited 24 Taiwanese students to interact with them in their created immersive environments. Analyses of the pre-service teachers' final written reflections showed that most of them reported that they experienced a sense of physical and social presence in their self-created VR environments and that they enjoyed participating in the VR project. However, various factors, such as the design of the task, technical difficulties with the VR equipment, and limits of the social VR network were also found to have negatively influenced their satisfaction with the VR experience. Findings from this study might inform other L2/FL teachers who design VR environments and integrate social VR in their classes. Suggestions for future research are also provided.

1. Université Laval, Canada; sabrina.priego@lli.ulaval.ca; https://orcid.org/0000-0003-0882-5456

2. National Taichung University of Education, Taiwan; meeilingliaw@gmail.com; https://orcid.org/0000-0002-0730-3659

How to cite this article: Priego, S., \& Liaw, M.-L. (2021). Exploring the efficacy of pre-service teachers as makers of virtual language/culture learning environments. Journal of Virtual Exchange, 4, 14-32. https://doi.org/10.21827/jve.4.37413 
Keywords: pre-service second language teachers, EFL students, virtual reality language/culture learning environments, maker approach to learning, physical and social presence.

\section{Introduction}

The integration of VR in L2 and FL learning contexts has attracted the attention of an increasing number of teachers and researchers (e.g. Berti, Maranzana, \& Monzingo, 2020; Chien, Hwang, \& Jong, 2020; Lan, 2020; Liaw, 2019; Priego \& Liaw, 2019; Shih, 2015). The two main features of VR, namely immersion and interaction, allow L2/FL learners both to practice the language and to develop their intercultural competence without leaving the classroom or their home countries. Immersion has been defined as the "framework where place illusion occurs, which is when a user believes that the virtual environment is real" (Yassien, Passant, Makled, \& Abdennadher, 2020, p. 2). As has been documented in the literature (e.g. Berti et al., 2020; Kaplan-Rakowski \& Gruber, 2019), the different levels of immersion are largely due to the equipment used to experience the VR. In low-immersion VR, learners use a standard two-dimensional monitor, a keyboard, or a mouse, whereas in highimmersion VR learners use a head-mounted system where their vision is fully enveloped, creating a sense of full immersion, which enhances the feeling of physical presence, that is, the sense of being in the physical environment from the first-person view (Bulu, 2012; Lan, 2020). In addition, social VR, such as Second Life (SL) ${ }^{3}$ and vTime ${ }^{4}$, allows learners to not only explore the environment, but also communicate with other people in different parts of the world, which may increase social presence (i.e. the sense of being with another in the virtual environment). From the viewpoint of social presence theory (Gunawardena, 1995), social presence is considered an essential element for promoting interaction among participants in virtual environments, and a predictor of learners' perceived learning outcomes (Lan, 2020; Lan, Kan, Sung, \& Chang, 2016; Witmer \& Singer, 1998) and learner satisfaction (Gunawardena \& Zittle, 1997). As such, social VR provides authentic learning experiences that have great potential for enhancing L2 skills and motivation (Chien et al., 2020; Lan, 2020; Lan et al., 2016; Liang, 2012; Yang, Chen, \& Jeng, 2010). For example, Lan et al. (2016) found that all the Chinese as an FL students participating in their study improved significantly in oral communication competence and appreciated the task-based activities designed in SL. More recently, Liaw's (2019) study on the potential of open social VR environments to provide English as a Foreign Language (EFL) university students with physical and social affordances for intercultural language learning showed evidence of Intercultural Communicative Competence (ICC) as defined by Byram's (1997) ICC model.

3. Second Life is a multiuser virtual environment launched by Linden Lab in 2003.

4. vTime (https://vtime.net/) is an open social VR network developed by vTime Limited that is a limited company incorporated in England and Wales. 
In regards to L2 teachers, the production of VR activities no longer requires high-tech capabilities, implying that most of them might be able to develop the learning content on their own. The idea of teachers creating their own VR environments and the possibility to share them with other teachers or with students is associated with what is called the 'Maker Movement' (Anderson, 2012; Niemeyer \& Gerber, 2015). As posited by Martin (2015), “one of the most readily apparent features of the Maker Movement is the celebration and use of new and newly affordable digital tools. As these tools provide new ways of interacting with physical materials, they also offer new opportunities for learning” (p. 32). In the same line of thought, Lan (2020) argues that "learning by experiencing, doing, or creating is now one of the most important trends in education, and has been associated with dramatic increases in the numbers of teachers and researchers trying to enhance student learning by including VR in their teaching” (p. 3). Another rationale for teachers to be makers of teaching materials is the need to provide learners with authentic contexts for L2 learning which has proven to be an important component for acquiring a new language (e.g. Chien et al., 2020; Lan, 2015, 2020). Besides the possibility to create 3D objects and scenes in low-immersive 3D virtual worlds, such as SL, nowadays L2 teachers can easily create 360 degree photos and videos by using a commercially available 360 degree 3D camera. These 360 degree photos and videos can then be shared in more deeply immersive VR to better meet the needs of their students (e.g. Berti et al., 2020; Lan, 2015, 2020; Papin, 2019).

Although many teacher education programs have at least some opportunities for students to learn about teaching and learning with maker technologies and principles, research on the integration of the Maker Movement in teacher preparation programs is only beginning to emerge (Cohen, 2017; Cohen, Jones, \& Smith, 2018; Corbat, 2018; Martin, 2015), and, to our knowledge, none of them have been conducted in the area of L2/FL teacher education. We believe that preparing future L2 teachers to meet the challenges and expectations of the 21st century demands giving them handson experience with cutting-edge technology. Also, FL learners need to be provided with authentic communication to be immersed in the cultural content. Thus, future L2 teachers, in addition to learning how to use VR technology, need to reflect on the affordances of immersive VR, including the sense of physical and social presence. To this end, we set up a VR project between a group of Canadian pre-service L2 teachers and a group of EFL Taiwanese students. Drawing on the benefits of VR 360 degree tasks reported in the literature (Berti et al., 2020; Lan, Lyu, \& Chin, 2019), the preservice L2 teachers used a 360 degree camera and VR software to design virtual environments that were used as cultural virtual tours in vTime. Then in groups, they met with EFL Taiwanese students in their self-created environment.

Considering the emerging important role of VR in the field of L2/FL instruction, the scarce attention to the analysis of physical and social presence in social VR from the makers' point of view, and the 
importance of presence in participants' satisfaction in online learning, this study is guided by the below research questions.

- What was the pre-service teachers' perceived sense of physical and social presence in their self-created VR environments?

- Were the pre-service teachers satisfied with the VR project?

- Did the pre-service teachers benefit from the VR project?

\section{Literature review}

As the project described in this paper involved EFL students and pre-service L2 teachers, in this section we first review studies that have investigated the use of VR in L2/FL learning, and then those related to VR in teacher education programs.

\subsection{Research on the use of VR in L2/FL language learning}

With the increasing popularity of VR in L2/FL learning, several literature reviews and meta-analyses have been conducted to gain a better understanding of how this technology is supporting language learning. For example, Lan's (2020) review paper describes the most recent VR applications that have potential benefits for FL learning. She classifies them into five categories: (1) visual experiences, (2) entertainment, (3) social networking, (4) operation, and (5) creation. She contends that "the increasing popularity of immersive VR means that better evidence is needed from research into immersive social VR for language learning in order to improve the understanding of the effects of immersion in social VR on FL learning” (p. 6).

Wang et al.'s (2020) reviewed studies related to the use of 3D Virtual Worlds (3DVWs) in L2/FL learning published between 2008 and 2019. In particular, their analysis focused on interaction and the impact on distinctive learning variables based on effect sizes. Their findings showed that students' interaction on 3DVWs substantially facilitates linguistic and affective gains. In addition, this meta-analysis confirmed the impact of 3DVWs on learners' communication skills and linguistic competence. They also showed the impact on learners' cognition and affection, which allowed the researchers to conclude that 3DVWs enhance students' attitude and self-efficacy, especially in collaborative learning conditions.

Another recent systematic review in the area of VR was conducted by Parmaxi (2020). The researcher analyzed and synthesized 26 papers published from 2015 to 2018, which were categorized under the following themes: (1) technologies used, language learning settings and duration of educational 
activities; (2) benefits and limitations of VR as an educational tool in the L2/FL classroom; and (3) future research directions regarding the educational use of VR. Their analyses show the potential of VR in L2/FL language learning and teaching, teamwork, autonomy, and cultural awareness. The review also outlines the limited inclusion of fully immersive VR in L2/FL classrooms, and calls for the need to conduct research using this type of technology.

\subsection{Research on the use of VR for second language learning involving teacher-made materials}

Literature in the area of 3DVWs in L2/FL learning also includes a number of studies in which the authors are the creators of the virtual environments. For example, Lan (2015) developed two virtual authentic contexts in SL to investigate the effects of VR in EFL learning and motivation of elementary-school students. In these virtual environments, the EFL students used their avatars to interact with the objects and with a non-player character. They then went to the immersive learning environment called the English Village where they interacted with a native English speaker. The results from a performance test created by the author showed that the created virtual environments significantly benefited the learners' oral skills, notably their syntactic and conversation abilities. In a more recent study conducted by Lan et al. (2019), the authors created virtual environments in SL to determine the impact of the immersive experience in SL on the essay-writing performance of 60 secondary school students studying Chinese as a Second Language (CSL) in Singapore. The objects in these virtual environments were labeled with keywords and sentences, which helped students to brainstorm ideas for their essays. An analysis of the writing plans showed that the 3D immersive experiences had a positive impact on the writing process of the CSL students.

In another study, Papin (2019) designed three communicative 360 degree VR tasks presenting learners with real-life communicative situations, such as paying for groceries, to evaluate the potential of 360 degree videos to lower international university students' anxiety and to increase their self-perceived communicative competence in French as an FL. The analysis of the students' learning journals showed that participants believed that 360 degree VR tasks had prepared them for real-life L2 interaction.

More recently, Berti et al. (2020) used three 360 degree VR videos recorded by one of them in the city of Bergamo, Italy, to investigate the influence of highly-immersive VR on Italian as an FL students' preconceived ideas of Italy and Italians. Findings from written reflections and focus group interviews showed that the 360 degree VR videos allowed students to reduce their use of stereotypes. The authors concluded that "highly immersive VR environments support students learning by providing personalized and contextualized learning opportunities that traditional materials do not offer” (Berti et al., 2020, p. 57). 


\subsection{Research on physical and social presence in virtual environments for second language learning}

Two types of presences are regarded central to the design of virtual environments for language learning (Chang, Sheldon, Si, \& Hand, 2012; Craddock, 2018): social presence and physical presence. Garrison, Anderson, and Archer (2000) define social presence as "the ability of participants in a community of inquiry to project themselves socially and emotionally, as 'real' people (i.e. their full personality), through the medium of communication being used” (p. 94). In a virtual learning community, social presence can play an essential role in learning.

Witmer and Singer (1998) describe physical presence as "the subjective experience of being in one place or environment, even when one is physically situated in another" (p. 225). According to the authors, the degree of physical presence depends on how much learners focus on what is happening in the virtual environment. Dalgarno and Lee (2010) add that when the environment is authentic and immersive, the learners are more likely to have interactions with objects and characters in it, and thus they have a higher sense of physical presence. As such, inducing high levels of social and physical presence to be perceived by the users is an important element of immersive systems. Other studies have found that the level of socio-spatial interactivity within the virtual environment affects the user's engagement in group-based activities (McCreery, Vallett, \& Clark, 2015) and that various factors, including immersive qualities, contextual properties, and individual traits affect the social presence within a given virtual environment (Oh, Bailenson, \& Welch, 2018).

\subsection{Research on the use of VR in teacher education programs}

As VR has the potential of enhancing learning opportunities in teacher education programs, several systematic reviews have been conducted to gain an understanding on how it is being used in teacher education programs. One of the most recent literature reviews was conducted by Billingsley, Smith, Smith, and Meritt (2019). They reviewed studies which employed immersive VR to extend knowledge and create learning experiences for pre-service and in-service teachers. In particular, this review included papers which had used immersive VR to teach skills associated with classroom or behavior management to advance learners' knowledge of special education topics, to deal with awareness of students' emotional needs, and to increase content area learning. All of these studies found that using fully immersive VR developed pre-service teachers' knowledge of certain learners' disabilities, increased their technological competence, and had a positive influence on their attitudes. Billingsley et al. (2019) concluded the following:

"VR technology could expose pre-service teachers to a larger variety of teaching and learning environments and experiences than what would be possible during a class lecture 
or practicum experience [...] using VR, pre-service teachers can practice many different scenarios, with varied outcomes, and repeat scenarios as often as needed under the supervision of teacher-educators” (p. 68).

\subsection{Research on physical and social presence in virtual environments in teacher education programs}

Most of the studies which have investigated physical and social presence in VR in the context of teacher education have used SL as a virtual environment. Among these, Bulu (2012) and Cho et al.'s (2015) studies are of particular relevance to the present study because their research designs included the four variables we aimed to analyze (i.e. physical presence, social presence, satisfaction, and benefits). Bulu (2012) investigated the relationships among physical presence, social presence, and co-presence in SL and their impact on the participants' satisfaction with this virtual environment. The participants were 46 pre-service teachers enrolled in a university in Turkey. They were asked to participate in synchronous role-playing activities to perform different teaching techniques in virtual environments. Analyses of a questionnaire adapted from previous studies (Kreijns, Kirschner, Jochems, \& van Buuren, 2007; Slater, Sadagic, Usoh, \& Shroeder, 2000; Slater, Steed, McCarthy, \& Maringelli, 1998; Slater, Usoh, \& Steed, 1994) showed a positive correlation among the types of presences. In particular, the pre-service teachers' answers to the questionnaire showed a close relationship between social presence and co-presence, as well as between physical and social presence. To investigate if the students' perceived physical, social, and co-presence influenced their satisfaction in the virtual worlds, a questionnaire adapted from Chou and Liu (2005) was used. The results showed that pre-service teachers' satisfaction was mostly determined by their perceived sense of social presence in the virtual environment. Physical presence and co-presence were also found to have a certain influence on learners' satisfaction.

In another study conducted among pre-service teachers enrolled in a university in Singapore, Cho et al. (2015) investigated the impact of physical and social presence on the participants' situational interest and perceived achievement in the tasks performed in SL. Based on Rotgans and Schmidt (2011), Cho et al. (2015) defined situational interest as "an immediate affective response to certain conditions and/or stimuli in the learning environment that focuses one's attention on the task, which may or may not last over time” (p. 72). The participating elementary pre-service teachers had to perform a mini lesson in SL. Similar to Bulu's (2012) study, the questionnaire on physical presence used by Cho et al. (2015) was adapted from the questionnaire developed by Slater et al. (1998). Results showed that although immediacy played a more important role than intimacy, immediacy was significantly correlated with co-presence and intimacy. The findings also showed a statistically significant influence of physical and social presence on the participants' situational interest and 
perceived achievement. However, similar to Bulu's (2012) study, Cho et al.'s (2015) study found that co-presence did not have a statistically significant influence on the participants' situational interest or perceived achievement.

In these studies, pre-service teachers participated as users of the VR environments. In this paper, we attempt to gain a better understanding of the affordances of virtual environments from the makers' point of view by analyzing (1) the pre-service teachers' perceived sense of physical and social presence in their self-created VR environments, (2) their satisfaction with the VR project, and (3) their opinions regarding the benefits of the VR project.

\section{Method}

\subsection{Context and participants}

A total of 22 pre-service L2 teachers who were taking a computer applications in second language teaching course at a university in Quebec, Canada, participated in this project. The group was composed of 18 Quebecer students, two French students, an Algerian student, and a Chinese student. In line with the Maker Movement, this course stressed hands-on experience and collaboration. The inclusion of the VR project in this class had the following objectives: allow pre-service teachers to (1) learn how to use a 360 degree camera, the VR equipment, and vTime, (2) learn how to create a VR cultural tour, (3) acquire first-hand experience in a VR environment, (4) reflect on the pedagogical potentials of including VR in their classrooms, and (5) develop intercultural skills.

The 24 EFL Taiwanese students participating in the VR project were enrolled in an undergraduate English oral training course at a university in Taiwan. Their participation in the VR project sought to (1) enable them to use English for interpersonal and intercultural communication, (2) give them opportunities for active participation in group discussions with confidence, (3) give them practice in active listening, (4) cultivate their ability to use information technological tools to communicate effectively, and (5) develop learner autonomy. None of the students in any of the two classes had previous experience in using the VR equipment or with social VR.

\subsection{VR equipment}

In Quebec, the pre-service teachers used a Vuze 4K 3D 360 degree spherical VR camera and a tripod to take the photos for their cultural virtual tours. They uploaded their 360 degree photos on vTime, a platform used as a social VR network to meet with the EFL Taiwanese students. As only one pair 
of Oculus Rift VR glasses was available for the pre-service teachers' use, each of them was also provided with a Google Cardboard headset ${ }^{5}$ to be used with their personal cell phone. FL students also used their personal cellphones and VR Box glasses were provided by their university.

\subsection{Design of the VR project}

The project was eight weeks in duration. At the beginning of the project, the participating pre-service teachers received training on how to use a 360 degree spherical VR camera and equipment. The instructors of both classes also showed students how to download vTime on their smartphones, how to meet with others in the VR environment, and how to customize their avatars.

Figure 1. Screen captures of two group meetings in vTime

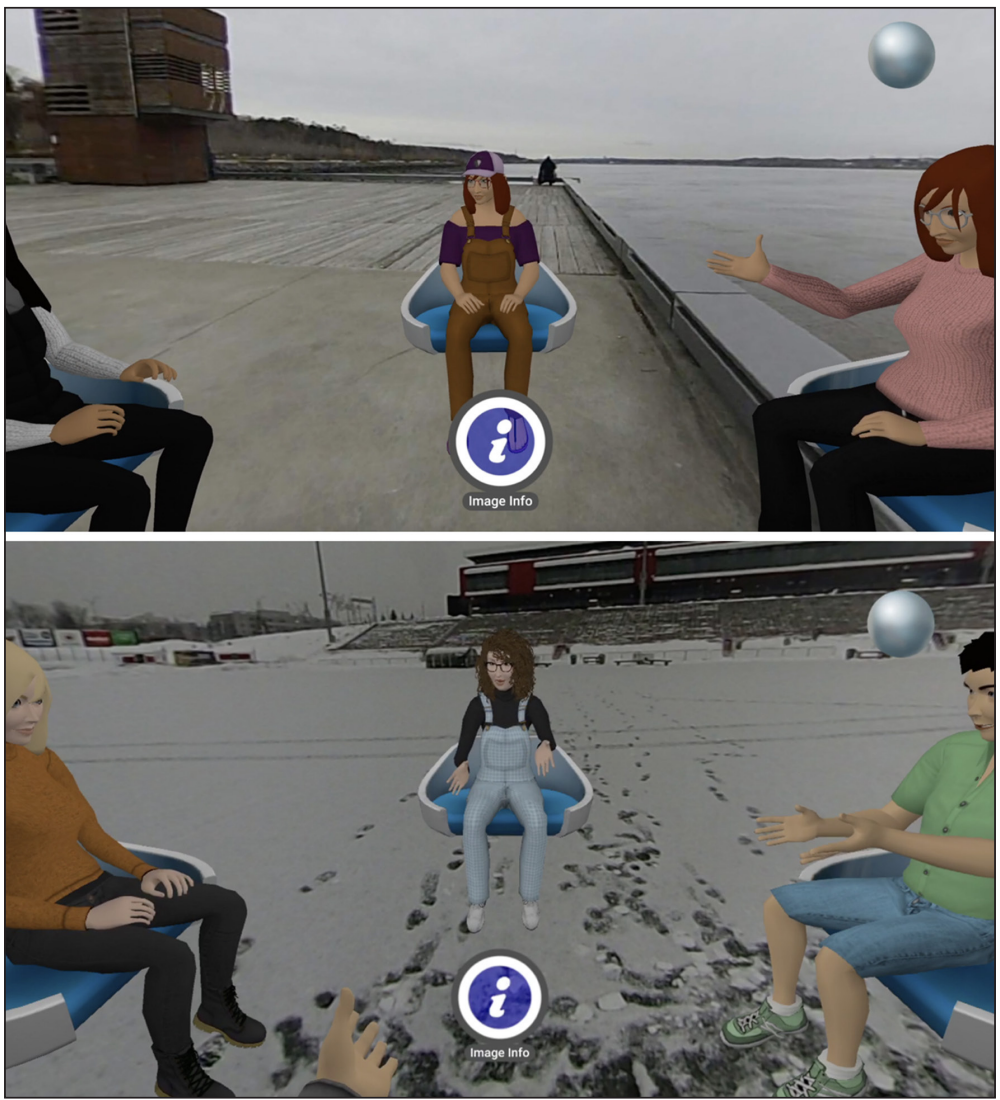

5. Google Cardboard, that utilizes the user's cell phone, is the most affordable and accessible way to replicate the basic functionalities of an Oculus Rift. 
We formed groups consisting of three pre-service teachers and two or three EFL students and asked them to establish a first contact on a Padlet ${ }^{6}$. Then, each group of pre-service teachers took a 360 degree photo of a place in Quebec. In particular, they took pictures of the TELUS Stadium, the National Museum of Fine Art, a Ceramic Coffee Shop, the University Football Field, the Samuel De-Champlain Pier, Myrand Avenue, and the University Hockey Arena. After that, they used their 360 degree photo to construct a cultural tour as an integral part of a mini lesson, aiming to prompt the discovery of a place in Quebec, to exchange cultural information, and to engage in discussion via the VR social network. Each group agreed on a moment to meet in vTime (see Figure 1 for two examples of group meetings in vTime). At the end of the project, the pre-service teachers were asked to reflect on the VR experience that had just concluded. The reflection contained open-ended questions divided into five sections: (1) participants' interest, enjoyment and motivation, (2) acquisition/development of pedagogical, technological, intercultural competences, (3) benefits, and (4) limits of the VR activity. The reflections were written on a Word document and the pre-service teachers had one week to submit them to the first author of this paper.

\section{Instruments and data analysis}

Prior to the beginning of the study, the pre-service teachers and EFL students signed a participation consent form. In analyzing the data, pseudonyms were used to protect participants' identities. To answer the three research questions outlined above, data from the pre-service teachers' final written reflections were analyzed using a content analysis approach. The reflections were read and codes allocated. Operational definitions of physical and social presence are based on previous literature in the area of virtual environments (Bulu, 2012; Biocca, Harms, \& Burgoon, 2003; Cho et al., 2015; Garrison et al., 2000; Gunawardena, 1995; Gunawardena \& Zittle, 1997; Wei \& Chen, 2012; Witmer \& Singer, 1998) and adapted to the present study. Physical presence is defined as the pre-service teachers' sense of being immersed in their self-created virtual environment. As for social presence, it is defined as the pre-service teachers' sense of being with another in the virtual environment. Based on Cho et al.'s (2015) and Wei \& Chen's (2012) studies, social presence was coded into three subcategories: (1) co-presence (i.e. the pre-service teachers' sensory awareness of other participants being in the same virtual space and the sense of being together), (2) intimacy (i.e. their perception of a close, bonded, and comfortable relationship with other participants), and (3) immediacy (i.e. their perception of intensity and directness in the interaction with other participants). The pre-service teachers' comments concerning their satisfaction with the VR project were coded either as positive or negative. As for their opinions regarding the benefits of the VR project, their comments were coded

6. Padlet (https://padlet.com) is a collaborative digital canvas that allows users to share and edit text, images, audio, and video. 
into three types: pedagogical knowledge, technological knowledge, and intercultural knowledge. This was an iterative process undertaken a number of times to increase validity of the coding. Inconsistent coding results were discussed until an agreement was reached by the two researchers.

\section{Findings and discussion}

\subsection{Pre-service teachers' perceived sense of physical and social presence in their self-created VR environments}

Most pre-service teachers reported that they had experienced a sense of physical presence in the VR environment they had created to meet with their Taiwanese teammates. For example, one of the pre-service teachers commented that the VR activity was "one of the rare opportunities we have to be in another country, while staying in the comfort of home or school” (Nicole).

Regarding the sense of social presence, some of them explicitly reported having experienced a sense of being together in the same virtual room, as the following excerpt illustrates: "Instead of just seeing the person on a screen, it was possible to feel in the same room as the other persons despite being separated by a long distance" (Audrey). However, some claimed that vTime had limited the interaction of all the members of the team because "the VTime app can connect up to four accounts at a time. This means that all six participants could not participate in the whole process of the activity” (Wendy).

The comments made by some of the participants demonstrate that they had established a close and comfortable relationship during the interaction in the VR environment. For example, Berthe said that "the Taiwanese were very kind and enthusiastic. They seemed motivated and interested in learning more about Quebec culture. They asked, among other things, if we could show them around if they ever come to Quebec for a few days". However, this bond does not seem to have been established by some groups. This was due, according to the pre-service teachers' reports, to the different expectations regarding the project. As reported by Louis, while for him and his fellow colleagues, the VR activity was primarily a learning activity, their Taiwanese partners were expecting to create a closer relationship with them.

With respect to the participants' perceptions of intensity and directness in interaction with other participants (i.e. immediacy), positive aspects mentioned by the pre-service teachers were related to the authenticity of the oral interaction activity due to the 360 degree photo and to the authentic contact with learners. The following excerpts exemplify such responses. 
"We believe that the activity allowed for a more authentic conversation, and despite the technical difficulties, having a picture promoted the discussion and allowed us to ask questions that we had not planned to ask” (Grace).

"Being able to talk to Taiwanese people was very interesting” (Barbara).

"It was more user-friendly and energetic than written-message conversations either via email or Facebook messaging. We laughed a lot during the VR experience together, even when there were technical difficulties" (Berthe).

However, several pre-service teachers also claimed that vTime had limited the interaction among participants. Most of the negative comments were related to the challenges moving their avatars in the VR environment and observing learners' non-verbal communication:

"Being unable to move in the picture limited us in the interaction. First, our movements were limited. It would have been advantageous, for certain questions, to be able to point to certain places or to be able to mimic certain elements of the questions” (Dorothée).

"I think that if we had been able to walk or even pick up objects during the activity, we would have been able to go deeper into the subject and ask more questions to the learners, so as to have a longer discussion and, therefore, more interaction” (Agnès).

"Since interactions are via avatars, it is rather difficult to see the level of motivation and enjoyment of learners. In fact, non-verbal communication cannot be observed" (Patricia).

"When animating the VR activity, I was able to identify some limitations: it is impossible to interpret the nonverbal signs that normally accompany the conversation, and that help to understand the conversation. During a communication in VR, the nonverbal signs are therefore more difficult to perceive since the person will not necessarily have the reflex to perform them when she has joysticks in her hands” (Béatrice).

\subsection{Pre-service teachers' satisfaction with the VR project}

Although all the pre-service teachers reported that they enjoyed participating in the VR project, some of them acknowledged the need to overcome some initial negative apprehensions due to the fear of the unknown as well as the time and investment it represented. 
"At first, I had some negative apprehensions because the time and workload seemed huge, but it was finally a little less difficult than I thought” (Rose).

"I had several initial apprehensions about the VR and its potential, I did not know if I was going to be able to carry out this task which seemed to me immense. However, I quickly had fun and I invested $110 \%$ in the activity. I left my comfort zone and discovered a tool with immense potentialities” (Barbara).

"Although initially I had rather negative apprehensions about VR, I think it was for fear of the unknown” (Hélène).

The novelty of this technology seems to have been the most important source of motivation, as these selected excerpts illustrate:

"I had fun throughout the project which allowed us, as a group, to learn a new way of learning” (Karim).

"I think this is an activity that arouses motivation and interest, because the medium is original and new: VR, at least for us, was absolutely unexplored and fascinating, so it generated positive reactions and curiosity” (Geneviève).

"In my opinion, this is a modern pedagogical activity to be exploited in order to motivate students and to look after their interests” (Rose).

Their motivation was also due to the objectives of the project, and the pleasure they experienced both in creating the VR environment and in participating in it:

"The nature of the project was enough to be motivated, since the objective of this activity concerns several aspects: educational, technological, and human” (Karim).

"I was looking forward to testing our VR project and that's mainly what motivated me" (Hélène).

"I was very interested in trying and using VR. I had fun performing the activity” (Dafne).

"I enjoyed doing the activity and piloting it” (Rita). 
Despite this manifested interest in the activity, Audrey expressed that she would have liked to learn more about her Taiwanese partners, but that this personal interaction among participants had been limited by the nature of the task:

"However, I would have liked to know more about Taiwanese. So I had a little less motivation for the discussion itself because we had to find some questions to ask about our city instead of learning new things” (Audrey).

In addition, the limits of vTime seems to have had a negative impact on some of the pre-service teachers' interest in this project, as manifested by Berthe:

"But apart from looking at the background and discussing, there is nothing that can be done concretely (moving in space, pointing specific objects, zooming - you cannot even choose the angle of the camera that takes groupies). At different times in the activity, it would have been relevant to have these options (to show what we talk about the different objects in the photo for example)" (Berthe).

\subsection{Pre-service teachers' perceived benefits of the VR project}

All the pre-service teachers reported to have benefited from the VR project. In particular, these benefits were related to the pedagogical, technical, and intercultural knowledge they gained as a result of creating VR environments and of using them as participants along with EFL learners.

From the pedagogical point of view, they expressed that they had discovered new ways to adapt their teaching strategies with distant learners.

"Thanks to this activity, I discovered a completely new way in which we could adapt teaching strategies to bring the learner closer to his daily reality, which is essentially based on technology" (Karim).

"I learned how to divide an activity into several parts, how to animate an activity within a time limit” (Dafne).

"I developed my ability to ask good questions. I learned how to create an educational activity using VR. I developed my ability to do classroom management through a VR headset, i.e. without being in direct contact with my interlocutor” (Barbara). 
"I believe that certain pedagogical skills that I acquired relate to having a conversation in a context where the interlocutor is not physically present” (Béatrice).

From the technological point of view, all of them reported to have reached the objectives of the course, namely, to learn how to create a VR activity and use the VR equipment and apps.

"I learned from A to Z how to use VR tools. I had never used Google Cardboard. In addition, I learned how to use a 360 degree camera. The vTime app was also unknown to me. If I had to do it, this activity allowed me to understand the application and I would be comfortable using it” (Dorothée).

"I had never used a 360 degree camera, so it was new to me. I also learned to use new applications like vTime that I did not know existed. I really liked the Google Cardboard and saw what they could offer despite their low prices, especially in a school context” (Grâce).

Finally, they expressed that they had developed their intercultural skills and acquired cultural information about Taiwan.

"I learned new information about the Taiwanese culture" (Diane).

"I learned how to define some concepts that seemed simple to me, but that were not simple for someone who is not used to my culture (for example: a café-ceramics) (Berthe).

"The VR activity allowed me to acquire some intercultural skills. First of all, it allowed me to become aware of the possible differences between my culture and the learners' culture. Moreover, the activity exploits these differences by asking learners to compare the landscape of photography with the landscapes of their country” (Béatrice).

\section{Conclusions and implications for future research}

This study analyzed the perceived sense of physical and social presence, the satisfaction with the VR project, and the opinions regarding the benefits of pre-service L2 teachers (the makers of the VR environments) who used social VR for EFL teaching purposes. Our findings allow us to conclude that most pre-service teachers experienced a sense of physical and social presence in the 360 degree environments they had created and that they benefited from this hands-on experience. However, it was also found that various factors, such as the design of the task, technical difficulties with the 
VR equipment, and limits of the social VR network, negatively influenced the satisfaction with the VR experience of some of them. It was also found that pre-service teachers' sense of intimacy and immediacy was affected by the use of avatars, namely the limited non-verbal behavior and the impossibility to move in the VR environment.

These results are in line with previous research that has highlighted the importance of avatars to be able to convey the users' actions in the VR environment. For instance, Cho et al. (2015) found that even if users see an avatar near their own avatar, "they may not have the sense of being together if the avatar does not move, make gestures, talk with other avatars, or show any intelligent behaviors" (p. 71). Bulu (2012) also found that a sense of intimacy and immediacy is influenced by verbal and non-verbal behaviors as well as the quality of communication technologies. Oh et al.'s (2018) findings showed that social presence positively correlates to enjoyment and trust. As for Yassien et al. (2020), they found that self-embodiment (i.e. the users' feeling of owning their virtual representation or avatar) and non-verbal cues are of paramount importance for designing an engaging social VR experience. It can thus be concluded, as Yassien et al. (2020) put it, that "a cornerstone challenge in designing an enjoyable and engaging social VR experience is supporting social presence” (p. 2).

The findings from the present study provide insights into the factors that affect the sense of physical and social presence in 360 degree VR environments from the makers' point of view. Despite the contributions, this study has a limitation in evaluating the sense of presence and satisfaction because it only used participants' self-reports. In order to more clearly understand the sense of presence and satisfaction of users and makers of VR environments, in future studies it will be necessary to include different instruments of data collection, such as interviews and content analyses of the interaction on the virtual environments. In addition, as in this project, preservice teachers only had access to one Oculus Rift VR headset, team members took turns using it while the others used the Google Cardboard headset. The insufficient number of devices for use with VR could have had an influence on the participants' perceived sense of social and physical presence in the VR environment. Future studies should compare physical and social presence when participants use VR glasses and hand controllers and when they use a Google Cardboard headset. Further studies should also investigate the sense of physical and social presence using other social VR environments that allow movement and verbal behavior of avatars, such as AltspaceVR and VIVE Sync. Finally, it would be necessary to investigate how the design of L2/FL language learning tasks influences physical and social presence in social VR environments. As it appears that the present study is the first to have investigated the affordances of 360 degree VR environments from the makers' point of view, findings from this study might inform other (L2/FL) teachers who design VR environments and integrate social VR in their classes. 


\section{Acknowledgments}

This study has been supported by a grant from Social Sciences and Humanities Research Council (Subventions exploratoires du CRSH) [Grant Number DR122614] and by the Ministry of Science and Technology in Taiwan [Grant Number MOST-107-2410-H-142 -010].

\section{References}

Anderson, C. (2012). Makers: the new industrial revolution. Grown Business.

Berti, M., Maranzana, S., \& Monzingo, J. (2020). Fostering cultural understanding with virtual reality: a look at students' stereotypes and beliefs. International Journal of Computer-Assisted Language Learning and Teaching, 10(1), 47-59.

Billingsley, G., Smith, S., Smith, S., \& Meritt, J. (2019). A systematic literature review of using immersive virtual reality technology in teacher education. Journal of Interactive Learning Research, 30(1), 65-90.

Biocca, F., Harms, C., \& Burgoon, J. K. (2003). Toward a more robust theory and measure of social presence: review and suggested criteria. Presence: Teleoperators and Virtual Environments, 12(5), 456-480.

Blyth, C. (2018). Immersive technologies and language learning. Foreign Language Annals, 51, 225-232.

Bulu, S. T. (2012). Place presence, social presence, co-presence, and satisfaction in virtual worlds. Computers \& Education, 58, 154-161.

Byram, M. (1997). Teaching and assessing intercultural communicative competence. Multilingual Matters.

Chang, B., Sheldon, L., Si, M., \& Hand, A. (2012). The engineering reality of virtual reality. Proceedings of SPIE-IS\&T Electronic Imaging, SPIE Vol. 8289, 828902. https://doi.org/10.1117/12.909835

Chien, S.-Y., Hwang, G.-J., \& Jong, M. S.-Y. (2020). Effects of peer assessment within the context of spherical video-based virtual reality on EFL students' English-speaking performance and learning perceptions. Computers \& Education, 146. https://doi.org/10.1016/j.compedu.2019.103751

Cho, Y. H., Yim, S. Y., \& Paik, S. (2015). Physical and social presence in 3D virtual role- play for pre-service teachers. Internet and Higher Education, 25, 70-77.

Chou, S. W., \& Liu, C. H. (2005). Learning effectiveness in a web-based virtual learning environment: a learner control perspective. Journal of Computer Assisted Learning, 21, 65-76.

Cohen, J. D. (2017). Maker principles and technologies in teacher education: a national survey. Journal of Technology and Teacher Education, 25(1), 5-30.

Cohen, J. D., Jones, W. M., \& Smith, S. (2018). Preservice and early career teachers' preconceptions and misconceptions about making in education. Journal of Digital Learning in Teacher Education, 34(1), 31-42, https://doi.org/10.1080/2 1532974.2017.1387832

Corbat, J. (2018). Teacher education in the makerspace: what might makerspaces afford for teacher education programs? Proceedings of SITE 2018 (pp. 1255-1259), Washington, DC. 
Craddock, I. M. (2018). Immersive virtual reality, Google Expeditions, and English language learning. Library Technology Reports, 54(4), 7-9.

Dalgarno, B., \& Lee, M. J. W. (2010). What are the learning affordances of 3-D virtual environments? British Journal of Educational Technology, 41, 10-32.

Garrison, D. R., Anderson, T., \& Archer, W. (2000). Critical inquiry in a text-based environment: computer conferencing in higher education. The Internet and Higher Education, 2, 87-105.

Gunawardena, C. N. (1995). Social presence theory and implications for interaction and collaborative learning in computer conferences. Paper presented at the 4th International Conference on Computer Assisted Instruction, Hsinchu, Taiwan.

Gunawardena, C. N., \& Zittle, F. J. (1997). Social presence as a predictor of satisfaction within a computer-mediated conferencing environment. The American Journal of Distance Education, 11(3), 8-26.

Kaplan-Rakowski, R., \& Gruber, A. (2019). Low-immersion versus high-immersion virtual reality: definitions, classification, and examples with a foreign language focus. Proceedings of the Innovation in Language Learning International Conference 2019. Pixel.

Kreijns, K., Kirschner, P. A., Jochems, W., \& van Buuren, H. (2007). Measuring perceived sociability of computersupported collaborative learning environments. Computers \& Education, 49, 176-192.

Lan, Y. J. (2015). Contextual EFL learning in a 3D virtual environment. Language Learning \& Technology, 19(2), 16-31. https://www.lltjournal.org/item/2898

Lan, Y. J. (2020). Immersion, interaction and experience-oriented learning: bringing virtual reality into FL learning. Language Learning \& Technology, 24(1), 1-15. http://hdl.handle.net/10125/44704

Lan, Y. J., Kan, Y. H., Sung, Y. T., \& Chang, K. E. (2016). Oral-performance language tasks for CSL beginners in Second Life. Language Learning \& Technology, 20(3), 60-79. https://www.lltjournal.org/item/2968

Lan, Y. J., Lyu, B. N., \& Chin, C. K. (2019). Does 3D immersive experience enhance Mandarin writing by CSL students? Language Learning \& Technology, 23(2), 125-144. https://doi.org/10125/44686

Liang, M. Y. (2012). Reimagining communicative context: ELF interaction in Second Life to learn EFL. Journal of Language, Identity, and Education, 11, 16-34.

Liaw, M.-L. (2019). EFL learners' intercultural communication in an open social virtual environment. Educational Technology \& Society, 22(2), 38-55.

Lloyd, A., Rogerson, S., \& Stead, G. (2017). Imagining the potential for using virtual reality technologies in language learning. In M. Carrier, R. M. Damerow, \& K. M. Bailey (Eds), Digital language learning and teaching: research, theory and practice (pp. 222-234). Routledge.

Martin, L. (2015). The promise of the Maker movement for education. Journal of Pre-College Engineering Education Research, 5(1), 30-39.

McCreery, M. P., Vallett, D. B., \& Clark, C. (2015). Social interaction in a virtual environment: examining socio-spatial interactivity and social presence using behavioral analytics. Computers in Human Behavior, 51, 203-206. https://doi. org/10.1016/j.chb.2015.04.044 
McKerlich, R., Riis, M., Anderson, T., \& Eastman, B. (2011). Student perceptions of teaching presence, social presence, and cognitive presence in a virtual world. MERLOT Journal of Online Learning and Teaching, 7(3), 324-336.

Niemeyer, D. J., \& Gerber, H. R. (2015). Maker culture and Minecraft: implications for the future of learning. Educational Media International, 52(3), 216-226.

Oh, C. S., Bailenson, J. N., \& Welch, G. F. (2018). A Systematic review of social presence: definition, antecedents, and implications. Frontier in Robotics and AI, 5, 114. https://doi.org/10.3389/frobt.2018.00114

Papin, K. (2019). La contribution des tâches de réalité virtuelle au désir de communiquer en français langue seconde à l'extérieur de la salle de classe à Montréal. Unpublished doctoral dissertation. Université de Montréal.

Parmaxi, A. (2020). Virtual reality in language learning: a systematic review and implications for research and practice. Interactive Learning Environments. https://doi.org/10.1080/10494820.2020.1765392

Peterson, M. (2011). Towards a research agenda for the use of three-dimensional virtual worlds in language learning. CALICO Journal, 29(1), 67-80.

Priego, S., \& Liaw, M.-L. (2019). Virtual reality participatory approach in foreign language learning and teacher training: is there an added value? Paper presented at EuroCALL Conference 2019. Louvain-la-Neuve, Belgium.

Rotgans, J. I., \& Schmidt, H. G. (2011). Situational interest and academic achievement in the active-learning classroom. Learning and Instruction, 21, 58-67.

Shih, Y.-C. (2015). A virtual walk through London: culture learning through a cultural immersion experience. Computer Assisted Language Learning, 28(5), 407-428.

Slater, M., Sadagic, A., Usoh, M., \& Shroeder, R. (2000). Small-group behavior in a virtual and real environment: a comparative study. Presence: Teleoperators and Virtual Environments, 9(1), 37-51.

Slater, M., Steed, A., McCarthy, J., \& Maringelli, F. (1998). The influence of body movement on presence in virtual environments. Human Factors: The Journal of the Human Factors and Ergonomics Society, 40(3).

Slater, M., Usoh, M., \& Steed, A. (1994). Depth of presence in virtual environments. Presence: Teleoperators and Virtual Environments, 3(2), 130-144.

Wang, C.-P., Lan, Y.-J., Tseng, W.-T., Lin, Y.-T. R., \& Gupta, C.-L. (2020). On the effects of 3D virtual worlds in language learning: a meta-analysis. Computer Assisted Language Learning, 33(8), 891-915. https://doi.org/10.1080/09588221.2019.1598444

Wang, M., Lawless-Reljic, S., Davies, M., \& Callaghan, V. (2011). Social presence in immersive 3D virtual learning environments. Proceedings from the International Symposium on Ambient Intelligence 2011, Salamanca, Spain.

Wei, C. W., \& Chen, N. S. (2012). A model for social presence in online classrooms. Educational Technology Research and Development, 60, 529-545.

Witmer, B. G, \& Singer, M. J. (1998). Measuring presence in virtual environments: a presence questionnaire. Presence: Teleoperators and Virtual Environments, 7(3), 225-240.

Yang, J. C., Chen, C. H., \& Jeng, M. C. (2010). Integrating video-capture virtual reality technology into a physically interactive learning environment for English learning. Computers \& Education, 55(3), 1346-1356.

Yassien, A., Passant, E., Makled, E., \& Abdennadher, S. (2020). A design space for social presence in VR. In Proceedings of the 11th Nordic Conference on Human-Computer Interaction: Shaping Experiences, Shaping Society (NordiCHI '20), Tallinn, Estonia. ACM, New York, NY, USA. https://doi.org/10.1145/3419249.3420112 


\section{Virtual Exchange?}

Published by University of Groningen Press | UGP, a not-for-profit press

Groningen, The Netherlands | UGP@rug.nl

(C) 2021 UNICollaboration (collective work)

(C) 2021 by Authors (individual work)

Journal of Virtual Exchange 2021

Edited by Carolin Fuchs and Müge Satar

Publication date: 2021/04/16

Journal of Virtual Exchange (JVE) is an online, open-access, peer-reviewed journal aimed at practitioners and researchers in the field known variously as virtual exchange, telecollaboration, or online intercultural exchange. It is the official journal of UNICollaboration (https://www.UNICollaboration.org/), the international academic organisation dedicated to supporting and promoting telecollaboration and virtual exchange in higher-level education.

Rights. The whole volume is published under the Attribution-NonCommercial-NoDerivatives 4.0 International licence (CC BY-NCND 4.0); individual articles may have a different licence. Under the CC BY-NC-ND licence, the volume is freely available online for anybody to read, download, copy, and redistribute provided that the author(s), editorial team, and publisher are properly cited. Commercial use and derivative works are, however, not permitted.

Disclaimer. University of Groningen Press does not take any responsibility for the content of the pages written by the authors of this article. The authors have recognised that the work described was not published before, or that it was not under consideration for publication elsewhere. While the information in this article is believed to be true and accurate on the date of its going to press, neither UniCollaboration nor University of Groningen Press can accept any legal responsibility for any errors or omissions. Additionally, the publisher makes no warranty, expressed or implied, with respect to the material contained herein. While University of Groningen Press is committed to publishing works of integrity, the words are the authors' alone.

Trademark notice. Product or corporate names may be trademarks or registered trademarks, and are used only for identification and explanation without intent to infringe.

Copyrighted material. Every effort has been made by the editorial team to trace copyright holders and to obtain their permission for the use of copyrighted material in this article. In the event of errors or omissions, please notify the publisher of any corrections that will need to by incorporated in future editions of this article.

Typeset by Research-publishing.net (https://research-publishing.net)

Noto fonts are open source. All Noto fonts are published under the SIL Open Font License, Version 1.1. Noto is a trademark of Google Inc. (https://www.google.com/get/noto/).

ISSN: 2647-4832 (online only)

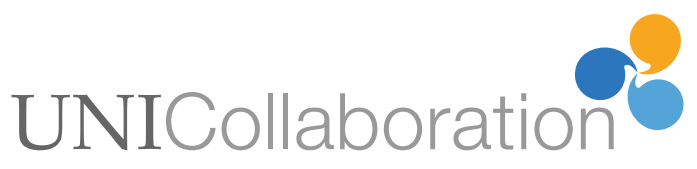

